\title{
Penerapan Metode Multi Attribute Utility Theory Pada Peserta Didik Penerimaan Bantuan Operasional Penyelenggara (BOP) Pendidikan Anak Usia Dini
}

\author{
Mona Debora Sinambela ${ }^{1}$, Handrizal' ${ }^{2}$ Irawan $^{3}$ \\ Program Studi Sistem Informasi, STIKOM Tunas Bangsa Pematangsiantar \\ Jln. Jendral Sudirman Blok A No. 1,2,3 Pematangsiantar \\ monadebora26@gmail.com
}

\begin{abstract}
Early Childhood Education (PAUD) is one of the government programs in guidance aimed at children from birth to the age of six years which is carried out through providing educational assistance to help growth and physical and spiritual development so that children have readiness in entering further education. MAUT application (Multi Attribute Utility Theory) is intended to select PAUD that has the right to get assistance from the government. Determination of policies taken as a basis for decision making, must use criteria that can be defined clearly and objectively. The criteria used as a requirement in the selection of receiving operational assistance (BOP) for early childhood education are parents 'work (C1), parents' income (C2), number of children (C3), number of children attending school (C4), number of college children (C5). The results of the calculation using the MAUT algorithm are alternatives that can receive the operational assistance of the organizer who has the highest value is alternative A1 with a value of 1 , alternative A3 with a value of 0.7, alternative $A 9$ with a value of 0.63 , alternative $A 7$ with a value of 0.46 , alternative A4 with a value of 0.43. Therefore, it can be concluded that the MAUT algorithm can be applied to VBNet-based applications where from the results of the calculation we get the similarity between the system and calculations using the MAUT algorithm. This research is expected to be a recommendation to the Principal in selecting the selection for receiving operational assistance for early childhood children at Kindergarten Daniel HKBP Tomuan Pematangsiantar.
\end{abstract}

Keywords: Early Childhood Education, MAUT, Decision Support System

Abstrak - Pendidikan Anak Usia Dini (PAUD) merupakan salah satu program pemerintah dalam pembinaan yang ditujukan bagi anak sejak lahir sampai dengan usia enam tahun yang dilakukan melalui pemberian ransangan pendidikan untuk membantu pertumbuhan dan perkembangan jasmani dan rohani agar anak memiliki kesiapan dalam memasuki pendidikan lebih lanjut. Penerapan MAUT (Multi Attribute Utility Theory) ditujukan untuk menyeleksi PAUD yang berhak mendapatkan bantuan dari pemerintah. Penentuan kebijakan yang di ambil sebagai dasar dalam pengambilan keputusan, harus menggunakan kriteria yang dapat terdefenisikan secara jelas dan objektif. Kriteria yang dijadikan syarat dalam pemilihan penerimaan bantuan operasional penyelenggara (BOP) pendidikan anak usia dini ini yaitu pekerjaan orang tua (C1), penghasilan orang tua (C2), jumlah banyak anak (C3), jumlah anak bersekolah (C4), jumlah anak kuliah (C5). Adapun hasil dari perhitungan dengan menggunakan algoritma MAUT yaitu alternatif yang dapat menerima bantuan operasional penyelenggara yang memiliki nilai tertinggi adalah alternatif A1 dengan nilai 1, alternatif $A 3$ dengan nilai 0,7, alternatif $A 9$ dengan nilai 0,63, alternatif $A 7$ dengan nilai 0,46, alternatif A4 dengan nilai 0,43. Maka dengan itu, dapat disimpulkan bahwa algoritma MAUT dapat diterapkan pada aplikasi berbasis VBNet dimana dari hasil perhitungan 
tersebut didapat kesamaan nilai antara sistem dan perhitungan menggunakan algoritma MAUT. Penelitian ini diharapkan dapat menjadi rekomendasi kepada Kepala sekolah dalam melakukan seleksi pemilihan penerimaan bantuan operasional penyelenggara bagi anak usia dini. di Taman Kanak - Kanak. Daniel HKBP Tomuan Pematangsiantar.

Kata Kunci: Pendidikan Anak Usia Dini, MAUT, Sistem PendukungKeputusan

\section{PENDAHULUAN}

Pendidikan merupakan hal yang sangat fundamental dengan mendapatkan pendidikan manusia memiliki pengetahuan yang dapat digunakan untuk bekerja dan pada akhirnya berguna dalam masyarakat. Sistem pendukung keputusan adalah bagian dari sistem informasi yang berbasis komputer yang digunakan untuk pengambilan keputusan dalam suatu organisasi. Management Decission System merupakan suatu sistem yang berbasis komputer dan membantu dalam pengambilan keputusan dengan memanfaatkan data-data dan model untuk menyelesaikan masalah yang tidak terstruktur[1]. Dimana standar pendidikan nasional tersebut terdiri atas standar isi, proses, kompetensi lulusan, tenaga pendidik dan tenaga kependidikan, TK Daniel Tomuan merupakan Suatu Taman Kanak-kanak yang memenuhi Standar Pendidikan Nasional. sarana dan prasarana, pengelolaan, pembiayaan, dan penilaian pendidikan. TK Daniel sangat membutuhkan dana Bantuan Operasional Penyelengaraan (BOP) karena bertujuan untuk meringankan biaya pendidikan bagi anak usia dini yang kurang mampu, agar mereka memperoleh layanan PAUD yang bermutu yang dapat membina, menumbuhkan, dan mengembangkan seluruh potensi anak usia dini secara optimal sehingga terbentuk perilaku dan kemampuan dasar sesuai dengan tahap perkembangannya. dalam aturan petunjuk teknis BOP PAUD yang mengatakan bahwa dalam menerima bantuan tersebut, setiap pengusul/PAUD harus memenuhi beberapa persyaratan dan kriteria dalam menerima BOP diantaranya harus memberikan kelengkapan berkas seperti : pekerjaan orang tua, penghasilan orang tua, jumlah banyak anak, jumlah anak bersekolah, jumlah anak kuliah dan kriteria tersebut lah yang ditetapkan oleh Bantuan Operasional Penyelengaraan (BOP).

Beberapa peneliti terdahulu telah dilakukan salah satunya adalah penelitian yang dilakukan oleh [2] dengan judul paper " Sistem Pendukung Keputusan Penentuan Penerima Bantuan Operasional Penyelengaraan (BOP) PAUD (Pendidikan Anak Usia Dini) Menerapkan Metode ELECTRE". Judul peneliti Putri Sianturi, Mesran, Putri Ramadhani, Nofri Wandi Al-Hafiz mengunakan 3 (Tiga) kriteria, dimana kesimpulan dari penulis adalah analisa sebuah sistem pendukung keputusan yang akan digunakan dalam menentukan penerimaan BOP yang bertujuan untuk memaksimalkan pengambilan keputusan terhadap penerimaan BOP. Perbedaan Dengan penelitian yang penulis lakukan saat ini, terdapat di penggunaan metode dan kriteria. Dimana kelebihan dari metode MAUT (Multi Attribute Utility Theory) yang penulis gunakan adalah untuk meyelesaikan suatu kriteria dalam sebuah metode, apabila metode tersebut memiliki konflik dalam menentukan relatifnya disetiap atributnya masing-masing. Dan kriteria yang digunakan penulis untuk menentukan Pendidikan Anak Usia Dini penerimaan BOP 
adalah pekerjaan orang tua, penghasilan orang tua, jumlah banyak anak, jumlah anak bersekolah, jumlah anak kuliah.

\section{METODOLOGI PENELITIAN}

\subsection{Sistem Pendukung Keputusan}

Sistem pendukung keputusan adalah bagian dari sistem informasi yang berbasis komputer yang digunakan untuk pengambilan keputusan dalam suatu organisasi. Management Decission System merupakan suatu sistem yang berbasis komputer dan membantu dalam pengambilan keputusan dengan memanfaatkan data-data dan model untuk menyelesaikan masalah yang tidak terstruktur [3][13].

\subsection{Multi-Attribute Utility Theory (MAUT)}

Multi-Attribute Utility Theory (MAUT) merupakan salah satu metode kuantitatif yang dijadikan dasarpengambilan keputusan melalui prosedur sistematis yangmengidentifikasi dan menganalisa beberapa variabel. Metode MAUT banyak digunakan untuk menyelesaikan pengambilan keputusan secara praktis. Hal ini disebabkan konsepnya sederhana dan mudah dipahami, komputasinya efisien, dan memiliki kemampuan mengukur kinerja relative dari alternatif-alternatif keputusan. Penelitian ini menggunakan 5 kriteria yaitu (C1) Pekerjaan orang tua, (C2) Penghasilan orang tua, (C3) Jumlah banyak anak, (C4) Jumlah anak bersekolah , dan (C5)Jumlah anak kuliah.

Beberapa langkah untuk mengembangkan Metode MAUT (Multi Atribute Utility Theory) sebagai berikut:[14]

1. Pecah sebuah keputusan ke dalam dimensi yang berbeda.

2. Tentukan bobot relatif pada masing-masing dimensi.

3. Daftar semua alternatif.

4. Masukkan utility untuk masing-masing alternatif sesuai atributnya.

5. Kalikan utility dengan bobot untuk menemukan nilai masing-masing alternatif.

$$
U_{(x)}=\frac{x-x i^{-}}{x i-x i^{+}}
$$

Keterangan :

$U_{(x)} \quad$ : Normalisasi Bobot Alternatif $\mathrm{x}$

$\mathrm{X} \quad$ : Bobot Alternatif

$x i^{-} \quad$ : Bobot Terburuk (minimum) dari kriteria ke-x

$x i^{+} \quad$ : Bobot Terbaik (Maksimum) dari kriteria ke-x

Dimana $\mathrm{U}(\mathrm{x})$ merupakan nilai normalisasi bobot alternatif $\mathrm{x}$, dimana $x i^{-}$ merupakan bobot terburuk (minimum) dan $x i^{+}$adalah bobot Terbaik (Tertinggi) dari setiap kriteria ke-x.

\subsection{Bantuan Operasional Penyelenggara (BOP)}


Bantuan Operasional Penyelenggaraan (BOP) merupakan Bantuan Operasional yang ditujukan kepada penyelenggara Pendidikan Anak Usia Dini (PAUD), yang bertujuan untuk meringankan beban biaya pendidikan bagi orang tua dalam upaya mengikutsertakan anaknya pada layanan PAUD berkualitas di Satuan PAUD atau Satuan Pendidikan Non Formal.

\section{HASIL DAN PEMBAHASAN}

\subsection{Penerapan Algoritma $M A U T$}

Data diperoleh dengan melakukan wawancara secara langsung kepada kepala sekolah di TK Daniel HKBP Tomuan pematangsiantar. Dari Hasil wawancara diperoleh beberapa kriteria yang dibutuhkan dari data siswa/i tahun $2017 / 2018$.

Tabel 1. Rating kecocokan setiap alternatif pada setiap kriteria

\begin{tabular}{|l|c|c|c|c|c|}
\hline \multirow{2}{*}{ Alternatif } & \multicolumn{5}{c|}{ Kriteria } \\
\cline { 2 - 6 } & C1 & C2 & C3 & C4 & C5 \\
\hline Elisabet Siregar & 0,9 & 0,9 & 0,9 & 0,5 & 0,5 \\
\hline Jordan Natpitupulu & 0,1 & 0,5 & 0,7 & 0,5 & 0,5 \\
\hline Sarah Sinaga & 0,9 & 0,9 & 0,7 & 0,5 & 0,3 \\
\hline Olivia Rumapea & 0,3 & 0,7 & 0,7 & 0,5 & 0,5 \\
\hline Justin Rumapea & 0,3 & 0,5 & 0,7 & 0,5 & 0,3 \\
\hline Rahel Napitupulu & 0,3 & 0,5 & 0,7 & 0,1 & 0,3 \\
\hline Margaretta Napitupulu & 0,1 & 0,5 & 0,9 & 0,5 & 0,5 \\
\hline Renold Tambunan & 0,1 & 0,3 & 0,9 & 0,5 & 0,5 \\
\hline Boloni Tampubolon & 0,9 & 0,7 & 0,7 & 0,5 & 0,3 \\
\hline Josua Simanjuntak & 0,4 & 0,7 & 0,7 & 0,5 & 0,3 \\
\hline Max & 0,9 & 0,9 & 0,9 & 0,5 & 0,5 \\
\hline Min & 0,1 & 0,3 & 0,7 & 0,1 & 0,3 \\
\hline
\end{tabular}

Tabel diatas menunjukkan rating kecocokan dari setiap alternatif pada setiap kriteria. Setelah melakukan penilaian dari setiap kriteria dengan bobot kriteria yang telah di tentukan, tahap selanjutnya adalah memberikan bobot preferensi dari setiap kriteria Peserta Didik, adapun bobot preferensinya yaitu :

1) Pekerjaan Orang Tua : 0,4

2) Penghasilan Orang Tua : 0,2

3) Jumlah Banyak Anak : 0,2

4) Jumlah Anak Bersekolah : 0,1

5) Jumlah Anak Kuliah : : 0,1

\subsection{Proses Perhitungan Metode MAUT}

Setelah penentuan Kriteria dan Alternatif dari Taman Kanak - kanak HKBP Tomuan maka tahap selanjutnya adalah pembuantan Matriks Ternormalisasi. berikut ini adalah matriks ternormalisasi :

Keterangan :

$U_{(x)} \quad$ : Normalisasi Bobot Alternatif $\mathrm{x}$

$\mathrm{x} \quad$ : Bobot Alternatif

$x i^{-} \quad$ : Bobot Terburuk (minimum) dari kriteria ke-x

$x i^{+} \quad$ : Bobot Terbaik (Maksimum) dari kriteria ke-x 
Dimana $\mathrm{U}(\mathrm{x})$ merupakan nilai normalisasi bobot alternatif $\mathrm{x}$, dimana $x i^{-}$ merupakan bobot terburuk (minimum) dan $x i^{+}$adalah bobot Terbaik (Tertinggi) dari setiap kriteria ke-x.

Perhitungan Normalisasi Matriks adalah sebagai berikut:
Anak $_{11}=\frac{0,9-0,1}{0,9-0,1}=1$
Anak $_{21}=\frac{0,9-0,3}{0,9-0,3}=1$
Anak $_{12}=\frac{0,1-0,1}{0,9-0,9}=0$
Anak $_{22}=\frac{0,5-0,3}{0,9-0,3}=0,33$
Anak $_{13}=\frac{0,9-0,1}{0,9-0,1}=1$
Anak $_{23}=\frac{0,9-0,3}{0,9-0,3}=1$
Anak $_{14}=\frac{0,3-0,1}{0,9-0,1}=0,25$
Anak $_{24}=\frac{0,7-0,3}{0,9-0,3}=0,67$
Anak $_{15}=\frac{0,3-0,1}{0,9-0,1}=0,25$
Anak $_{25}=\frac{0,5-0,3}{0,9-0,3}=0,33$

.... dst sampai Anak 10

.... dst sampai Anak 210

$\operatorname{Anak}_{31}=\frac{0,9-0,7}{0,9-0,7}=1$

Anak $_{41}=\frac{0,5-0,1}{0,5-0,1}=1$

Anak $_{32}=\frac{0,7-0,7}{0,9-0,7}=0$

Anak $_{42}=\frac{0,5-0,1}{0,5-0,1}=1$

Anak $_{33}=\frac{0,7-0,7}{0,9-0,7}=0$

Anak $_{43}=\frac{0,5-0,1}{0,5-0,1}=1$

Anak $_{34}=\frac{0,7-0,7}{0,9-0,7}=0$

Anak $_{44}=\frac{0,5-0,1}{0,5-0,1}=1$

Anak $_{35}=\frac{0,7-0,7}{0,9-0,7}=0$

Anak $_{45}=\frac{0,5-0,1}{0,5-0,1}=1$

... dst sampai Anak310

... dst sampai Anak410

$\operatorname{Anak}_{51}=\frac{0,5-0,3}{0,5-0,3}=1$

Anak $_{52}=\frac{0,5-0,3}{0,5-0,3}=1$

Anak $_{53}=\frac{0,3-0,3}{0,3-0,3}=0$

Anak $_{54}=\frac{0,5-0,3}{0,5-0,3}=1$

Anak $_{55}=\frac{0,3-0,3}{0,5-0,3}=0$

... dst sampai Anak510

Tabel 2. Hasil Normalisasi Matriks

\begin{tabular}{|c|c|c|c|c|c|}
\hline \multirow{2}{*}{ Alternatif } & \multicolumn{5}{|c|}{ Kriteria } \\
\cline { 2 - 6 } & C1 & C2 & C3 & C4 & C5 \\
\hline Elisabet Siregar & 1 & 1 & 1 & 1 & 1 \\
\hline Jordan Natpitupulu & 0 & 0,33 & 0 & 1 & 1 \\
\hline Sarah Sinaga & 1 & 1 & 0 & 1 & 0 \\
\hline
\end{tabular}

Penerapan Metode MAUT Pada Peserta Didik Penerimaan BOP PAUD (Mona D Sinambela) | 568 


\begin{tabular}{|c|c|c|c|c|c|}
\hline \multirow{2}{*}{ Alternatif } & \multicolumn{5}{|c|}{ Kriteria } \\
\cline { 2 - 6 } & C1 & C2 & C3 & C4 & C5 \\
\hline Olivia Rumapea & 0,25 & 0,67 & 0 & 1 & 1 \\
\hline Justin Rumapea & 0,25 & 0,33 & 0 & 1 & 0 \\
\hline Rahel Napitupulu & 0,25 & 0,33 & 0 & 0 & 0 \\
\hline Margaretta Napitupulu & 0 & 0,33 & 1 & 1 & 1 \\
\hline Renold Tambunan & 0 & 0 & 1 & 1 & 1 \\
\hline Boloni Tampubolon & 1 & 0,67 & 0 & 1 & 0 \\
\hline Josua Simanjuntak & 0,375 & 0,67 & 0 & 1 & 0 \\
\hline
\end{tabular}

Tahap selanjutnya akan dilakukan perkalian matrik normalisasi dengan bobot preferensi dengan menggunakan rumus:

$\mathrm{V}(\mathrm{X}) \sum_{\mathrm{i}=1}^{\mathrm{n}} \mathrm{Wj} . \mathrm{Xij}$

Dimana $\mathrm{V}(\mathrm{x})$ merupakan nilai evaluasi dari sebuah objek ke i dan wi merupakan bobot yang menentukan nilai dari seberapa penting elemen ke i terhadap elemen lainnya. Sedangkan n merupakan jumlah elemen.

Berikut Perhitungan perkalian matriks Normalisasi dengan menggunakan persamaan (1) :

Anak $1=(0,4 * 1)+(0,2 * 1)+(0,2 * 1)+(0,1 * 1)+(0,1 * 1)=1$

Anak $2=(0,4 * 0)+(0,2 * 0,33)+(0,2 * 0)+(0,1 * 1)+(0,1 * 1)=0,26667$

Anak $3=(0,4 * 1)+(0,2 * 1)+(0,2 * 0)+(0,1 * 1)+(0,1 * 0)=0,7$

Anak $4=(0,4 * 0,25)+(0,2 * 0,67)+(0,2 * 0)+(0,1 * 1)+(0,1 * 1)=0,43333$

Anak $5=(0,4 *-0,25)+(0,2 * 0,33)+(0,2 * 0)+(0,1 * 1)+(0,1 * 0,1)=0,26667$

Anak $6=(0,4 * 0,25)+(0,2 * 33)+(0,2 * 0)+(0,1 * 0)+(0,1 * 0)=0,16667$

Anak $7=(0,4 * 0)+(0,2 * 0,33)+(0,2 * 1)+(0,1 * 1)+(0,1 * 1)=0,46667$

Anak $8=(0,4 * 0)+(0,2 * 0)+(0,2 * 1)+(0,1 * 1)+(0,1 * 1)=0,4$

Anak $9=(0,4 * 1)+(0,2 * 0,67)+(0,2 * 0)+(0,1 * 1)+(0,1 * 0)=0,63333$

Anak $10=(0,4 * 0,375)+(0,2 * 67)+(0,2 * 0)+(0,1 * 1)+(0,1 * 0)=0,38333$

Dari hasil perkalian matrik yang dilakukan maka kita dapat menentukan perengkingan terhadap penerimaan bantuan operasional Penyelenggara. Berikut ini adalah perengkingan yang dri setiap alternatif.

Tabel 3. Perengkingan

\begin{tabular}{|c|l|c|c|}
\hline No. & \multicolumn{1}{|c|}{ Alternatif } & Hasil & Rangking \\
\hline 1. & Elisabet Siregar & 1 & 1 \\
\hline 2. & Jordan Natpitupulu & 0,26667 & 8 \\
\hline 3. & Sarah Sinaga & 0,7 & 2 \\
\hline 4. & Olivia Rumapea & 0,43333 & 5 \\
\hline 5. & Justin Rumapea & 0,26667 & 9 \\
\hline 6. & Rahel Napitupulu & 0,16667 & 10 \\
\hline 7. & Margaretta Napitupulu & 0,46667 & 4 \\
\hline 8. & Renold Tambunan & 0,4 & 6 \\
\hline 9. & Boloni Tampubolon & 0,63333 & 3 \\
\hline 10. & Josua Simanjuntak & 0,38333 & 7 \\
\hline
\end{tabular}


Dengan menentukan perengkingan dari setiap alternatif, maka dapat disimpulkan bahwa 5 alternatif yang sangat layak di usulkan menjadi Penerimaan Bantuan Operasional Penyelenggara (BOP) Yaitu : Elisabet Siregar, Sarah Sinaga, Boloni Tampubolon, Margaretta Napitupulu, dan Olivia Rumapea.

\subsection{Input Data Penilaian Siswa Menggunakan VB.Net 10}

Nilai perbandingan didapat dengan membandingkan alternatif satu dengan alternatif yang lain dimana hasil akhir dijumlahkan lalu dibagi dengan banyaknya kriteria. Tampilan nilai perbandingan dapat dilihat pada gambar 1 berikut:

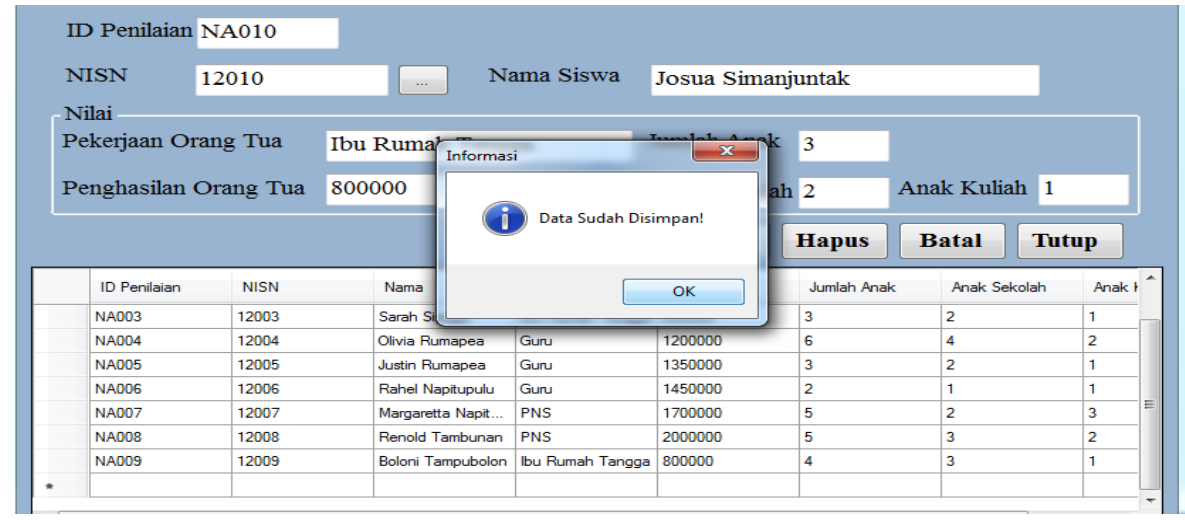

Gambar 1. Data Penilaian Siswa

\subsection{Hasil Perangkingan Menggunakan VB.Net 10}

Dengan menentukan perengkingan dari setiap alternatif, maka dapat disimpulkan bahwa 5 alternatif yang sangat layak di usulkan menjadi Penerimaan Bantuan Operasional Penyelenggara (BOP) Yaitu : Elisabet Siregar, Sarah Sinaga, Boloni Tampubolon, Margaretta Napitupulu, dan Olivia Rumapea. Tampilan hasil akhir dapat dilihat pada gambar 2 dan gambar 3 . berikut:

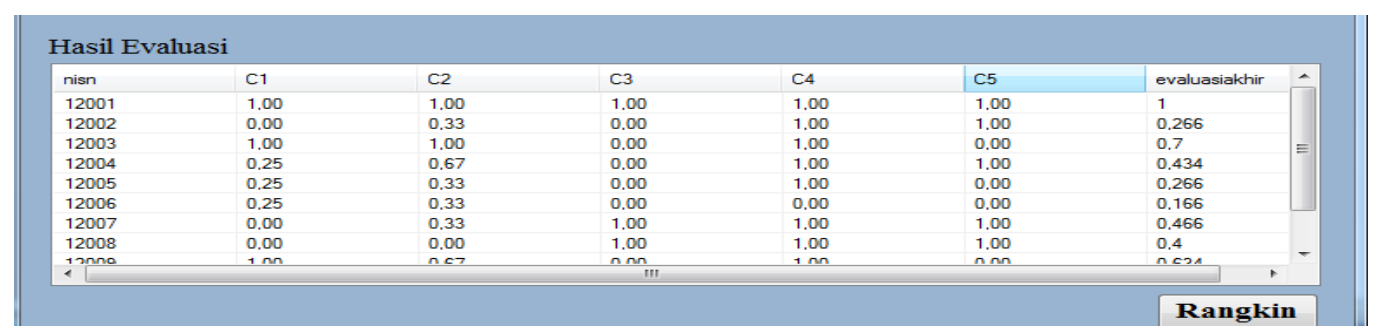

Gambar 2. Hasil Akhir 


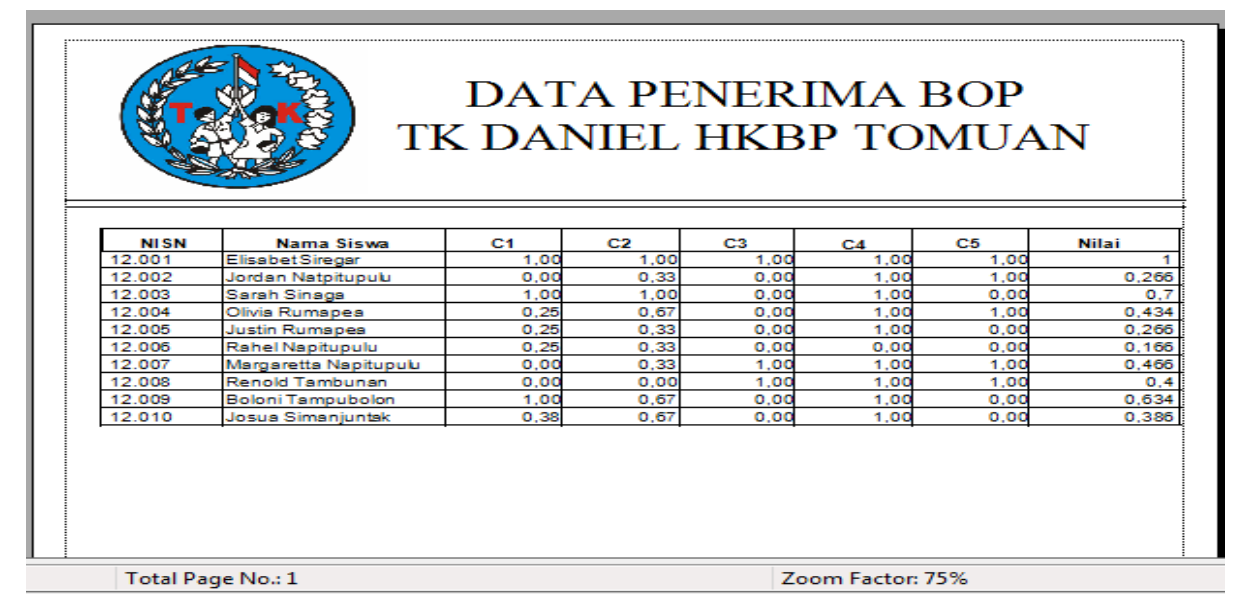

Gambar 3. Laporan Hasil Perhitungan Dan Penerimaan BOP

\section{KESIMPULAN}

Setelah melakukan penelitian lapangan, analisis data, perancangan, dan perhitungan komputerisasi yang telah dilakukan, maka diperoleh kesimpulan dalam menentukan siswa penerima BOP sebagai berikut:

a) Dari hasil perhitungan dengan menggunakan Metode Maut dalam penentuan pemilihan calon penerima BOP maka alternatif yang berhak medapatkan bantuan operasional penyelenggara (BOP) dengan urutan tertinggi sampai terendah yaitu alternatif A1 dengan nilai 1, alternatif A3 dengan nilai 0,7, alternatif A9 dengan nilai 0,63, alternatif A7 dengan nilai 0,46 dan alternatif A4 dengan nilai 0,43 . Maka dengan itu, dapat disimpulkan bahwa algoritma maut dapat diterapkan pada aplikasi berbasis vebnet dimana dari hasil perhitungan tersebut didapat kesamaan nilai antara sistem dan perhitungan menggunakan algoritma maut. Dari hasil perhitungan tersebut dapat menjadi rekomendasi kepada Taman Kanak - Kanak Daniel HKBP Tomuan dalam penentuan pemilihan calon penerima BOP.

b) Aplikasi yang dibuat hanya sebagai alat bantu utuk memberikan informasi kepada user atau pihak sekolah sebagai bahan pertimbangan dalam menentukan siswa yang menerima BOP.

\section{DAFTAR PUSTAKA}

[1] S. R. Rani, R. Rizka, and A. Perdana, "Analisis Metode Profile Matching Pada Rekomendasi Cat Dinding Rumah Berdasarkan Konsumen," vol. 17, 2018.

[2] P. Sianturi, P. Ramadhani, and N. W. Al-hafiz, "SISTEM PENDUKUNG KEPUTUSAN PENENTUAN PENERIMA BANTUAN OPERASIONAL PENYELENGARAAN ( BOP ) PAUD ( PENDIDIKAN ANAK USIA DINI ) MENERAPKAN METODE ELECTRE ( STUDI KASUS : DINAS PENDIDIKAN KABUPATEN SIMALUNGUN )," vol. I, pp. 20-26, 2017.

[3] R. A. Hutasoit, S. Solikhun, and A. Wanto, "Analisa Pemilihan Barista dengan Menggunakan Metode TOPSIS (Studi Kasus: Mo Coffee),” KOMIK (Konferensi Nasional Teknologi Informasi dan Komputer), vol. 2, no. 1, pp. 256-262, 2018.

[4] T. Imandasari, A. Wanto, and A. P. Windarto, "Analisis Pengambilan Keputusan Dalam Menentukan Mahasiswa PKL Menggunakan Metode PROMETHEE," Jurnal Riset Komputer (JURIKOM), vol. 5, no. 3, pp. 234-239, 2018.

[5] M. Masitha, D. Hartama, and A. Wanto, "Analisa Metode (AHP) pada Pembelian Sepatu Sekolah Berdasarkan Konsumen," Seminar Nasional Sains \& Teknologi Informasi (SENSASI), Penerapan Metode MAUT Pada Peserta Didik Penerimaan BOP PAUD (Mona D Sinambela)|571 
vol. 1, no. 1, pp. 338-342, 2018.

[6] S. R. Ningsih, D. Hartama, A. Wanto, I. Parlina, and Solikhun, "Penerapan Sistem Pendukung Keputusan Pada Pemilihan Objek Wisata di Simalungun," in Seminar Nasional Teknologi Komputer \& Sains (SAINTEKS), 2019, pp. 731-735.

[7] L. P. Purba, A. P. Windarto, and A. Wanto, "Faktor Terbesar Rendahnya Minat Ber-KB (Keluarga Berencana) dengan Metode ELECTRE II," Seminar Nasional Sains \& Teknologi Informasi (SENSASI), vol. 1, no. 1, pp. 369-374, 2018.

[8] N. Rofiqo, A. P. Windarto, and A. Wanto, "Penerapan Metode VIKOR Pada Faktor Penyebab Rendahnya Minat Mahasiswa Dalam Menulis Artikel Ilmiah," Seminar Nasional Sains \& Teknologi Informasi (SENSASI), vol. 1, no. 1, pp. 228-237, 2018.

[9] S. Sundari, S. M. Sinaga, I. S. Damanik, and A. Wanto, "Sistem Pendukung Keputusan Pemilihan Peserta Olimpiade Matematika SMA Swasta Teladan Pematangsiantar Dengan Metode Electre," in Seminar Nasional Teknologi Komputer \& Sains (SAINTEKS), 2019, pp. 793-799.

[10] S. Sundari, A. Wanto, Saifullah, and I. Gunawan, "Sistem Pendukung Keputusan Dengan Menggunakan Metode Electre Dalam Merekomendasikan Dosen Berprestasi Bidang Ilmu Komputer (Study Kasus di AMIK \& STIKOM Tunas Bangsa)," in Seminar Nasional Multi Disiplin Ilmu, 2017, pp. 1-6.

[11] A. Wanto and H. Damanik, "Analisis Penerapan Sistem Pendukung Keputusan Terhadap Seleksi Penerima Beasiswa BBM (Bantuan Belajar Mahasiswa) Pada Perguruan Tinggi Menggunakan Metode Simple Additive Weighting (SAW) (Studi Kasus : AMIK Tunas Bangsa Pematangsiantar)," in Seminar Nasional Rekayasa (SNTR) II, 2015, no. 2, pp. 323-333.

[12] A. Wanto and E. Kurniawan, "Seleksi Penerimaan Asisten Laboratorium Menggunakan Algoritma AHP Pada AMIK-STIKOM Tunas Bangsa Pematangsiantar," Jurnal Informatika dan Komputer (JIKO), vol. 3, no. 1, pp. 11-18, 2018.

[13] M. Widyasuti, A. Wanto, D. Hartama, and E. Purwanto, "Rekomendasi Penjualan Aksesoris Handphone Menggunakan Metode Analitycal Hierarchy Process (AHP)," Konferensi Nasional Teknologi Informasi dan Komputer (KOMIK), vol. I, no. 1, pp. 27-32, 2017.

[14] N. Hadinata, "Implementasi Metode Multi Attribute Utility Theory ( MAUT ) Pada Sistem Pendukung Keputusan dalam Menentukan Penerima Kredit," vol. 7, no. September, pp. 8792, 2018. 